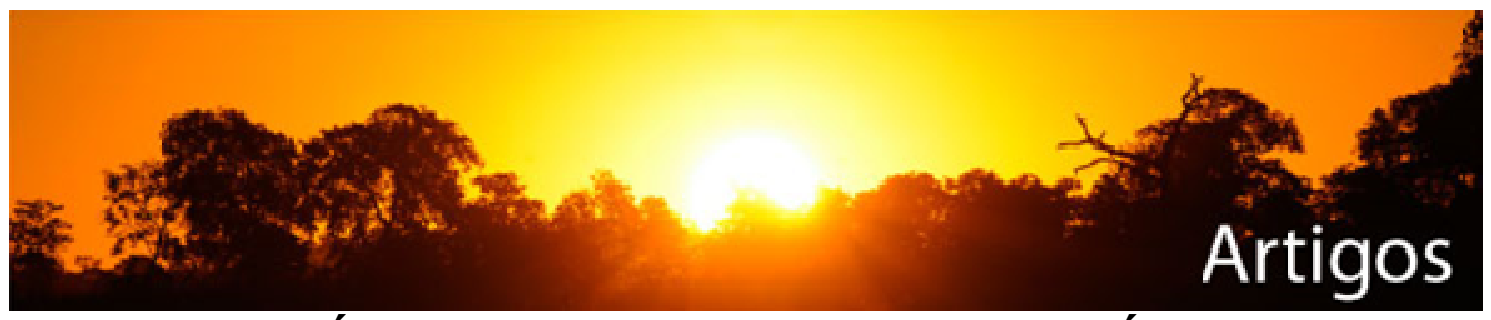

\title{
A LOGÍSTICA REVERSA COMO ESTRATÉGIA DE COMPETITIVIDADE
}

Brunno Henrique de Souza Santiago'

\begin{abstract}
RESUMO
O maior alvo das empresas tem sido, claramente, o econômico ou de agregação de valor monetário, entretanto a introdução da Logística Reversa vem sendo visto como um dos principais fatores para a competitividade e a preocupação ambiental. O objetivo do estudo foi analisar a possibilidade de que a logística reversa gere condições reais de competitividade entre as empresas. Realizou-se busca de literatura nas bases de dados: Lilacs, Scielo. $\mathrm{Na}$ maioria dos autores que embasaram este artigo, a competitividade apresenta-se em destaque, diante dos resultados, para a motivação das empresas adotarem e olhar com mais preocupação para a Logística Reversa.
\end{abstract}

PALAVRAS-CHAVE: Logística; logística reversa; competitividade de mercado.

\footnotetext{
${ }^{1}$ Mestre em engenharia. Engenheiro dos Materiais com Especialização em Materiais Metálicos, Poliméricos e Cerâmicos) pela Universidade Federal do Rio Grande do Norte - UFRN. E-mail: bunnohenrique@yahoo.com.br
} 


\section{INTRODUÇÃO}

O percurso rumo ao desenvolvimento econômico juntamente com as diretrizes que regem a sustentabilidade têm sido envolto por grandes problematizações e desafios ao passo que persiste uma consciência social ainda limitada sobre as implicações do modelo de desenvolvimento em curso. O limiar do século XXI está sendo marcado por um forte apelo para o fato de que não há desenvolvimento econômico sem desenvolvimento social e ecológico, onde esta ideia ficou bem definida a partir da teoria do desenvolvimento econômico segundo os estudos de Castro (2004).

Segundo Felizardo (2005), os consumidores desenvolvem uma má visão da organização empresarial se a empresa for de encontro às políticas ambientais. Por esta razão, elas têm sido cada vez mais utilizadas nas escolhas mercadológicas, inserindo assim, as estratégias competitivas sustentáveis tornando a empresa focada e bem posicionada no mercado de atuação para com seus concorrentes.

O maior alvo das empresas tem sido, claramente, o econômico ou de agregação de valor monetário, entretanto a introdução da $L R$ vem sendo visto como um dos principais fatores para a competitividade e a preocupação ambiental, sendo estas bases para os processos de sustentabilidade organizacional (LEITE, 2003).

O presente artigo justifica-se pela importância que a Logística reversa tem no âmbito do planejamento estratégico para que a empresa apresente, simultaneamente, visão econômica, social e ecológica. Nesta perspectiva, o objetivo é analisar a possibilidade de que a logística reversa gere condições reais de competitividade entre as empresas na visão dos empresários.

\section{REVISÃO DE LITERATURA}

\subsection{Logística Reversa}

Enquanto a logística tradicional trata do fluxo de saída dos produtos, a logística reversa se preocupa com o retorno de produtos, materiais e peças ao processo de produção da empresa, sendo dessa forma considerada uma R. gest. sust. ambient., Florianópolis, v. 5, n. 2, p. 20-28,out.2016/mar. 2017. 
evolução da logística. Logística Reversa se refere a todas as atividades logísticas de coletar, desmontar e processar produtos e/ou materiais e peças usados a fim de assegurar uma recuperação sustentável (REVLOG, 2001)

A Lei Federal № 12.305 de 02 de agosto de 2010, também conhecida como Política Nacional de Resíduos Sólidos (PNRS), estabeleceu que a responsabilidade pelo ciclo de vida dos produtos seja compartilhada entre seus fabricantes, importadores, distribuidores e comerciantes, o que impulsiona a logística reversa.

Segundo Daher (2006), as principais razões que levam as empresas a atuarem em Logística Reversa, são: a Legislação Ambiental que força as empresas a retornarem seus produtos e cuidar do tratamento necessário; os benefícios econômicos do uso de produtos que retornam ao processo de produção, ao invés dos altos custos do correto descarte do lixo; a crescente conscientização ambiental dos consumidores; Razões competitivas; a limpeza do canal de distribuição; a proteção de Margem de Lucro; a recaptura de valor e recuperação de ativos. 
De acordo com um estudo de campo intitulado Logística Reversa, realizado em maio de 2015 por alunos da Devry(JP) sendo parte deles autores deste mesmo artigo, tomando como objeto de estudo a empresa M Dias Branco, a prática de LR foi aderida para diminuir a quantidade de lixo nos aterros sanitários e a empresa também lucrava com a prática, e os entrevistados ressaltaram a importância de vantagens como ajudar ao meio ambiente bem como a imagem da empresa. Logo abaixo, segue 0 mapeamento dos processos da LR oriundo da rotina da empresa M. Dias Branco.

Figura 1 - Fluxo dos processos da Logística reversa

Fonte: M. Dias Branco, 2015.

\section{(Fonte: Temas tecnológicos em fundamentos de gestão. Devry-Jp, 2015)}

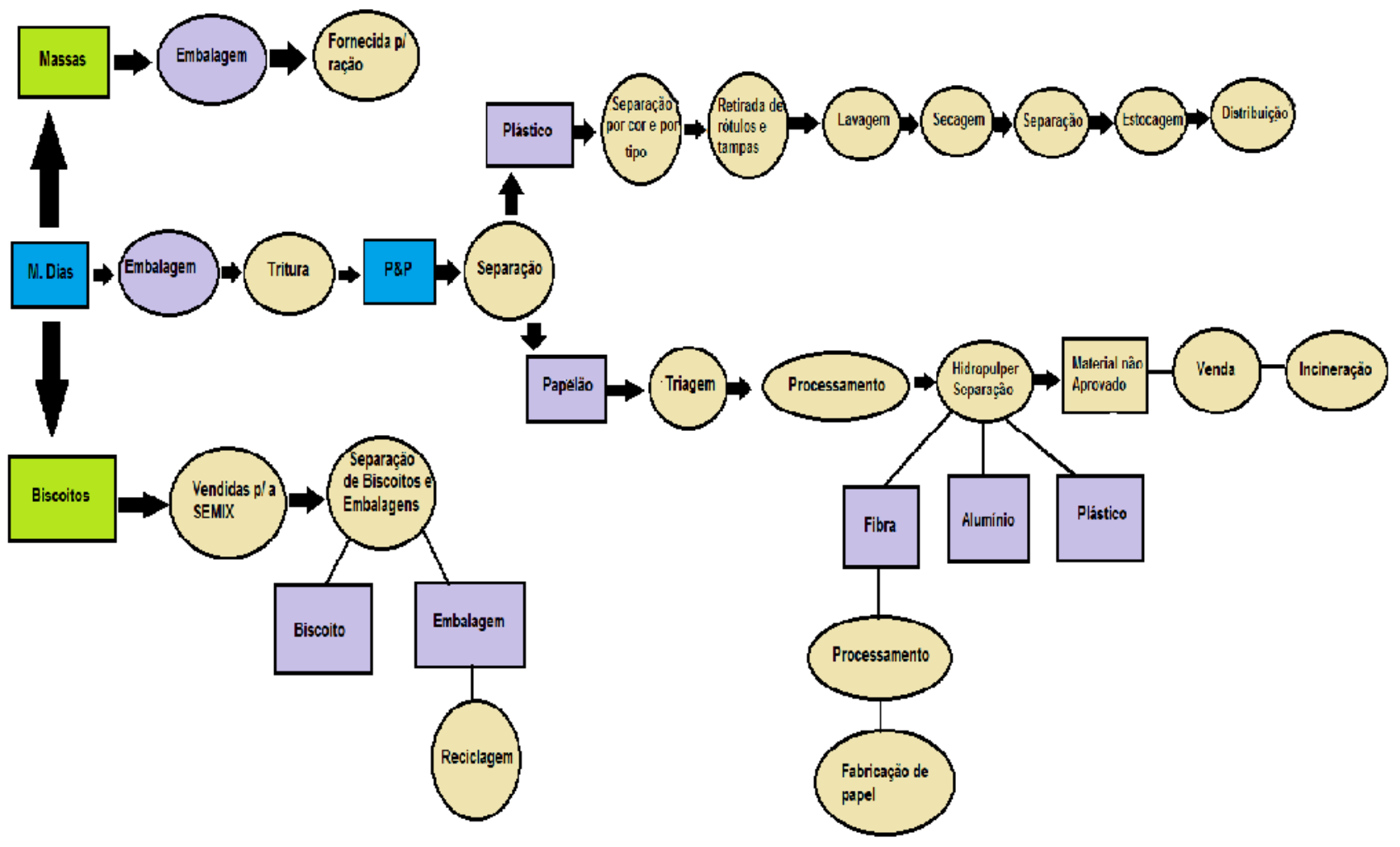

\subsection{Competitividade}

R. gest. sust. ambient., Florianópolis, v. 5, n. 2, p. 20-28,out.2016/mar. 2017. 
O termo "competitividade", aplicado tanto às nações como às empresas, está em voga, devido às mudanças no cenário mundial. As ideias de economistas heterodoxos, como Schumpeter (1931), ajudam-nos a compreender o papel da diversificação e da inovação na tentativa das empresas de evitar a concorrência direta.

A fidelização procura construir laços de relacionamento envolvendo e encantando o cliente, procurando com isso manter o consumo frequente, pois a manutenção de uma organização no mercado é a sua capacidade de reter os seus clientes. "Um ponto importante a se ressaltar é que, ao perder um cliente, geralmente não se perde somente uma venda, mas potencialmente uma vida inteira de vendas" (BEE, 2000, p.13).

Assim sendo, Pires (2004) e Saen (2009) afirmam que as organizações observaram que este tema pode ser convertido de um problema para uma grande vantagem competitiva. Contribui Leite (2003) dizendo que, ao praticar a logística reversa, as empresas agregam valor de diversas naturezas: econômica, ecológica, legal, logística, entre outras, minimizando os impactos negativos ao meio ambiente estabelecendo parcerias para construir as suas redes logística reversas, reaproveitando recursos existentes, projetando novos produtos que minimizem os impactos, comercializando os resíduos entre outros.

\section{METODOLOGIA}

Trata-se de um estudo de caráter exploratório, por meio de uma pesquisa bibliográfica, que segundo Gil (2008), "é desenvolvida a partir de material já elaborado, constituído de livros e artigos científicos." As fontes utilizadas foram: Lilacs; Scielo; trabalhos monográficos da FADERGS (Faculdade de Desenvolvimento do Rio Grande do Sul).

\section{RESULTADOS E DISCUSSÃO}


Diante das consultas realizadas a artigos acadêmicos abordando o tema da LR e a competitividade, pôde-se observar alguns dados significativos encontrados pelos autores dos artigos científicos. As empresas modernas estão utilizando a logística reversa, própria ou contratada de empresas especializadas, como forma de aumento de sua competitividade no mercado. Pesquisa realizada com cerca de 70 empresas de vários setores apontam diversos motivos estratégicos para a adoção de atividades de logística reversa nas empresas, conforme mostrado na tabela abaixo.

Tabela 1 - O percentual da motivação pela adoção da Logística Reversa

\begin{tabular}{|c|c|}
\hline Motivo Estratégico & Porcentagem das respostas \\
\hline Aumento de Competitividade & $65 \%$ \\
\hline Limpeza de Canal - estoque & $33 \%$ \\
\hline Respeito à Legislação & $29 \%$ \\
\hline Revalorização & $28 \%$ \\
\hline Recuperação de ativos & $27 \%$ \\
\hline
\end{tabular}

Fonte: Leite (2003).

De acordo com os resultados obtidos nesta experiência de coleta de dados obtendo as informações a cerca do real motivo estratégico para que se adote as políticas ambientais com foco na Logística Reversa, dentre eles, a limpeza de Canal - estoque, o respeito à Legislação, a Revalorização do produto, a recuperação de ativos, a competitividade apresenta-se, significantemente, em primeiro lugar com percentual de $65 \%$ das respostas individuais ou combinadas com outras das opções de respostas mencionadas.

O estudioso Porter (1989, p. 31) afirma que vantagem competitiva não pode ser compreendida observando-se a empresa como um todo. Ela tem sua origem nas inúmeras atividades distintas que uma empresa executa no projeto, na produção, no marketing, na entrega e no suporte ao seu produto. Cada uma destas atividades pode contribuir para a posição dos custos relativos de uma empresa, além de criar uma base para diferenciação.

De acordo com Leite (2003), uma forma de ganho de vantagem competitiva frente aos concorrentes é a garantia de políticas liberais de retorno de produtos (estratégia de minimizar as barreiras para retorno e troca de R. gest. sust. ambient., Florianópolis, v. 5, n. 2, p. 20-28,out.2016/mar. 2017. 
produtos) que fidelizem os clientes. Dessa forma, empresas que possuem um processo de logística reversa bem gerido tendem a se sobressair no mercado, uma vez que podem atender aos seus clientes de forma melhor e diferenciada do que seus concorrentes.

Indo de encontro a todos esses fatores mencionados até então, uma pesquisa realizada buscando averiguar se os consumidores valorizavam a coleta de embalagens recicláveis mostrou que a logística reversa não é um fator de influência na decisão sobre o local de compra. Outros fatores como proximidade, preço e variedade dos produtos prevalecem nesta escolha, como encontrado por outros autores (Furuta, 2002); (Xavier, 2005), conforme demonstrado na Figura 2 abaixo.

Figura 2 - Fatores que influenciam a escolha do local de compra para os consumidores no Rio de Janeiro

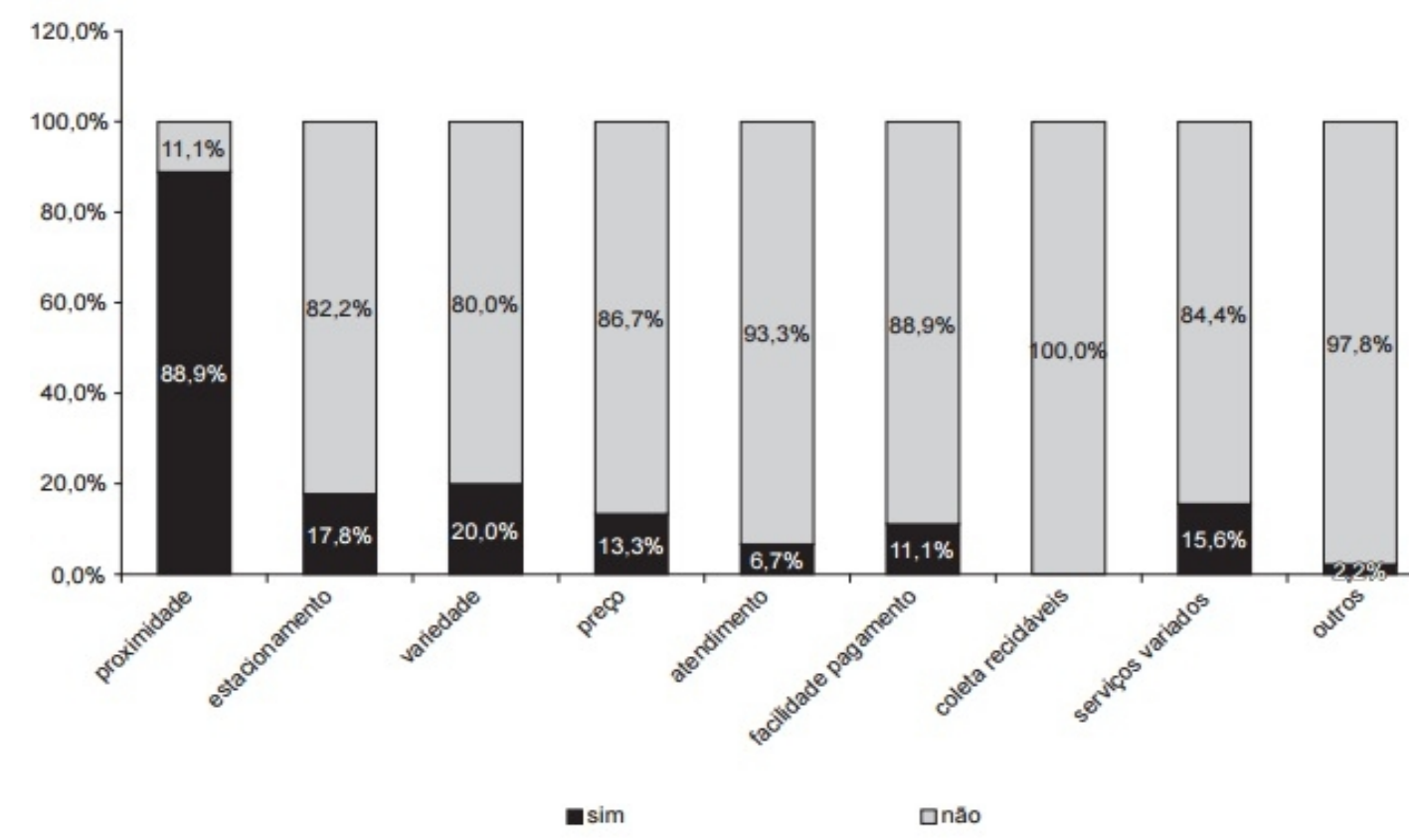

Fonte: Departamento de Engenharia de Produção, Universidade Federal de São Carlos UFSCAR, 2015.

De acordo com o gráfico, a Logística reversa não entra como um dos principais fatores de escolha do local de compra, mas sim a proximidade e em seguida a variedade dos produtos quando apresentam-se em maior percentual das respostas da pesquisa aos consumidores da cidade do Rio de Janeiro. 


\title{
5 CONSIDERAÇÕES FINAIS
}

Tomando como base todos os artigos pesquisados, os trabalhos consultados, incluindo a pesquisa realizada em Maio de 2015 abordando o tema da Logística Reversa através do estudo de campa com a empresa $\mathrm{M}$ DIAS BRANCO, e, por excelência, aquele que mais fundamentou o presente artigo, o livro Logística Reversa: meio ambiente e competitividade do autor Leite (2003), pode-se concluir que, para grande parte dos autores que embasaram este artigo, além da prática da Logística Reversa contribuir para a estrutura ecológica da preservação do planeta a partir de uma visão sustentável, ela possui influência significativa na competitividade entre as empresas sendo, portanto, um motivo real para que o mercado a adote como prática de rotina. Entretanto, abordando os estudos de Xavier (2005) e Furuta(2002), a Logística Reversa não é vista como estratégia de competitividade perante $\mathrm{o}$ resultado dos dados obtidos a partir do questionamento dos consumidores. Faz-se necessário, portanto, novos estudos para conclusões mais objetivas.

\section{THE REVERSE LOGISTICS AS COMPETITIVE STRATEGY}

\begin{abstract}
The biggest target companies have been clearly economic or aggregation of monetary value, however the introduction of reverse logistics has been seen as a key factor for competitiveness and environmental concerns. The aim of the study was to analyze the possibility that reverse logistics generate real competitive conditions between companies. We conducted literature search in databases: Lilacs, Scielo. Most of the authors that supported this article, competitiveness presents highlighted, given the results, for the motivation of companies to adopt and look more concern for Reverse Logistics.
\end{abstract}

Key-words: Logistics; reverse logistic; market and competitiveness.

\section{REFERÊNCIAS}

R. gest. sust. ambient., Florianópolis, v. 5, n. 2, p. 20-28,out.2016/mar. 2017. 
BEE, R. Fidelizar o cliente. 2.ed. São Paulo: Nobel, 2000

CASTRO, B. A.; ARAÚJO, M. A. D. de. Gestão dos resíduos sólidos sob a ótica da Agenda 21: um estudo de caso em uma cidade nordestina. Revista de Administração Pública. Rio de Janeiro, v. 38, n. 4, p. 561-587, jul./ago. 2004.

DAHER, Cecílio E., SILVA, Edwin P. S., FONSECA, Adelaida P.; Logística Reversa: Oportunidade para Redução de Custos Através do Gerenciamento da Cadeia Integrada de Valor.

FELIZARDO, J. M.. Logística Reversa: competitividade com desenvolvimento sustentável. 1. ed. Rio de Janeiro: Papel Virtual, 2005.

FURUTA, E.C.; Razões de escolha de supermercados de vizinhança como local de compra. 2002. Faculdade de Economia, Administração e Contabilidade, Universidade de São Paulo. São Paulo, 2002.

LEITE, P. R. Logística Reversa: meio ambiente e competitividade. 1. ed. São Paulo: Prentice Hall, 2003.

MARIOTTO, F.L.; O conceito de competitividade da empresa: uma análise crítica. Rev. adm. empres. vol.31 no.2 São Paulo, 1991.

PIRES, S. R. I. Gestão da cadeia de suprimentos: conceitos, estratégias, práticas e casos. São Paulo: Atlas, 2004.

SAEN, R.F. A new model for selecting third-party reverse logistics providers in the presence of multiple dual-role factors. Springer-Verlag London Limited, 2009.

XAVIER, F. M.; A Formulação da Estratégia de Operações como Fator de Melhoria da Competitividade no Varejo. 2005. Tese (Doutorado em Engenharia de Produção) - Departamento de Engenharia de Produção, Universidade Federal de Santa Catarina. Florianópolis, 2005. 